\title{
O Programa Institucional de Bolsa de Iniciação à Docência de Química (PIBID): reflexões para a formação docente
}

The Programa Institucional de Bolsa de Iniciação à Docência (PIBID): reflections for teacher training

\author{
G. L. S. Barbosa ${ }^{1 *}$, J. A. de Souza ${ }^{1}$, R. de C. Suart ${ }^{1}$ \\ ${ }^{1}$ Departamento de Química/Laboratório de Ensino de Química, Universidade Federal de Lavras, 37200-000, \\ Lavras- MG, Brasil
}

*gis_leticia@hotmail.com

(Recebido em 04 de maio de 2015; aceito em 13 de julho de 2015)

\begin{abstract}
O PIBID é um programa que visa a formação inicial de professores. Suas ações vêm se consolidando desde que foi implantado, em 2008, e é realidade em várias instituições de ensino superior no Brasil. Tendo em vista a relevância desse programa em âmbito nacional, analisa-se nesse trabalho a motivação dos estudantes da Licenciatura em Química de uma Universidade do sul de Minas Gerais ao ingressarem nesse programa, bem como, as expectativas dos professores em formação inicial com relação à contribuição desse programa para a formação docente. Foram realizadas entrevistas semi-estruturadas com doze participantes do PIBID/Química durante o segundo período letivo do ano de 2013. Os resultados mostram que, embora alguns licenciandos tenham iniciado o curso sem compreenderem o verdadeiro papel da docência, a participação no PIBID parece estar contribuindo para uma imersão dos futuros professores na prática profissional, bem como, aumentando o interesse deles em seguirem a carreira docente.

Palavras-chaves: formação docente, PIBID, licenciatura.
\end{abstract}

PIBID is a program that aim pre service chemistry teaching. Their actions have been consolidated since it was implemented in 2008 and is reality in various institutions of higher education in Brazil. In view of the importance of this program nationwide, is analyzed in this paper the pre service chemistry motivation of a University in Minas Gerais to admission this program as well as their expectations with respect to the contribution that for teacher training. Semi-structured interviews were conducted with twelve participants during the second semester of 2013. The results show that although some undergraduates have started the course without understanding the true role of teaching, participation in PIBID appears to be contributing to a immersion of future teachers in professional practice as well, increasing their interest in follow the teaching career.

Keywords: teacher training; PIBID; initial academic studies

\section{INTRODUÇÃO}

Recentemente, no Brasil, algumas ações vêm sendo tomadas a fim de incentivar a docência e valorizar os cursos de licenciatura. Uma das medidas tomadas pelo Governo Federal é o Programa Institucional de Bolsas de Iniciação à Docência (PIBID). Esse projeto vem sendo implantado em várias instituições de ensino superior e, atualmente, concede bolsas de iniciação à docência para muitos licenciandos em todo o país.

Observando a relevância do programa para a formação de professores, considerou-se importante pesquisar o impacto do PIBID na formação docente de seus integrantes, e quais aspectos motivacionais os estudantes de licenciatura demonstram ao ingressarem e desenvolverem atividades no programa, ou seja: Quais os objetivos são buscados pelos 
estudantes quando procuram ingressar no PIBID? Que expectativas esses estudantes têm em relação ao programa? E, Todos eles querem seguir a carreira docente na educação básica?

Assim, nesse trabalho objetiva-se conhecer as motivações inicias dos estudantes participantes do PIBID/Química de uma Universidade Mineira em relação ao programa e os impactos do PIBID na sua formação inicial, avaliando as motivações, anseios e perspectivas dos professores em formação inicial pela carreira docente.

\section{A formação de professores}

Atualmente, percebe-se que existe uma ampla divulgação nos discursos a respeito da melhoria na educação, principalmente com relação à formação de professores. De acordo com Maldaner (2006) [1], é consensual a ideia de que a formação de professores deve ser contínua, indo muito além da graduação, e desse modo, se aceita a concepção da complexidade da ação pedagógica como um todo e, especialmente, da formação de professores.

Segundo Pereira (1999) [2], no Brasil, as licenciaturas foram criadas dentro das faculdades de filosofia, em consequência, principalmente, da preocupação com a regulamentação da preparação de docentes para a escola secundária. Esse autor afirma ainda que essas licenciaturas eram propostas segundo a fórmula " $3+1$ ". Essa fórmula consistia em cursos de licenciatura com duração prevista de quatro anos, nos quais as disciplinas de conteúdo específico tinham duração de três anos, e antecediam as disciplinas de natureza pedagógica, com duração prevista de um ano. Algumas críticas são apontadas por Pereira (1999) [2] ao modelo " 3 + 1", como por exemplo: a separação entre prática e teoria, a priorização da formação teórica em detrimento à formação prática, e a concepção da prática como um simples espaço de aplicação da teoria. $\mathrm{O}$ mesmo autor afirma ainda que um equívoco desse modelo é assumir que, para ser um bom docente, necessita-se apenas de conhecimento específico da área que vai lecionar.

Ainda de acordo com Pereira (1999) [2], nesta forma de se conceber a formação docente, o professor é visto como um técnico, um especialista que aplica as regras que vem do conhecimento pedagógico e do conhecimento científico, e para formar esse professor, é preciso um conjunto de disciplinas científicas e outro conjunto de disciplinas pedagógicas, que fornecerão as bases para sua ação. Ainda, seriam nos estágios supervisionados que o professor em formação inicial desenvolveria tais conhecimentos e habilidades científicas e pedagógicas para as realidades da sala de aula.

No entanto, embora décadas tenham passado e o formato " $3+1$ " tenha sido extinto na grande maioria das universidades, a formação de professores parece ainda baseada nos preceitos dessa metodologia.

Schnetzler e Aragão (1995) [3] afirmam que é comum encontrarmos professores que apresentam uma visão simplista da docência em virtude de cursos de licenciatura pouco eficientes para a formação de docentes. Ainda de acordo com as autoras, isso se deve ao fato de muitos cursos conceberem que basta ter conhecimento específico e fazer uso de certas técnicas pedagógicas para ensinar, uma vez que a função do ensino é transmitir conhecimentos que deverão ser retidos pelos estudantes. Essa forma de ensino é conhecida como ensino tradicional.

Maldaner (2006) [1] afirma que os professores universitários se comprometem pouco com a questão da formação de professores e com a sua autoformação pedagógica, deixando para outro grupo, geralmente externo ao curso, a formação didático-pedagógica dos seus alunos que almejam exercer o magistério. Esse autor afirma ainda que os professores que atuam na formação pedagógica percebem, nos estudantes de licenciatura, a falta de uma visão clara e mais consistente dos conteúdos, que lhes permita uma reelaboração pedagógica, tornando-os plausíveis para a aprendizagem das crianças e adolescentes. No entanto, os professores das áreas pedagógicas estão fora do contexto do curso, e afastados da realidade escolar, e por isso não conseguem suprir as lacunas deixadas nesse particular, nem romper com a formação implícita em Química [1].

Benite, Benite e Echeverria (2010) [4], também afirmam que existe a formação profissional específica em conteúdos como prática de formação inicial docente. Os mesmos autores afirmam ainda que nessa prática, a falta da perspectiva pedagógica pode levar a situações 
comprometedoras à mediação necessária para a significação dos conceitos científicos. Os autores declaram que as questões pedagógicas, que deveriam acompanhar os conteúdos químicos, não estarão presentes se não houve uma incorporação do conhecimento pedagógico originado em pesquisas educacionais.

Em posse desses conhecimentos, nota-se uma necessidade de que sejam tomadas medidas que melhorem a formação inicial dos professores, e uma delas pode ser o Programa Institucional de Bolsas de Iniciação à Docência (PIBID).

Assim, nessa pesquisa objetiva-se conhecer as motivações inicias dos estudantes do PIBID/Química de uma Universidade Mineira em relação ao programa, e os impactos gerados pelo PIBID na formação inicial de seus integrantes.

\section{O PIBID}

Até 2007, quando o PIBID foi anunciado, existiam bolsas destinadas à iniciação científica para graduandos e outras bolsas de aperfeiçoamento profissional, como as bolsas de mestrado e doutorado para alunos da pós-graduação. Não havia ainda um programa destinado a apoiar os estudantes que objetivavam lecionar na Educação Básica. Inicialmente, a criação de bolsas para o programa PIBID foi destinada especialmente para as áreas de Química, Física, Biologia e Matemática, que eram as áreas nas quais havia carência de professores em formação inicial. Desde então, o Programa vem se consolidando e atualmente já é uma realidade na maior parte dos cursos de licenciatura das diversas áreas, em instituições de todo o país.

De acordo como Ministério da Educação e Cultura (MEC) [5], o PIBID procura antecipar o vínculo entre as salas de aula da rede pública e os futuros professores, prevendo que os últimos se envolvam nas atividades realizadas pelas escolas participantes do programa. Consequentemente, espera-se uma articulação entre as faculdades, as escolas que atendam a educação básica e as secretarias municipais e estaduais, bem como docentes e discentes.

Paredes e Guimarães (2012) [6] definem o PIBID como um programa que tem sido uma aposta do governo federal para promover uma mudança de cultura da formação de professores no Brasil, uma vez que, o programa investe em ações que visam à valorização e o reconhecimento das licenciaturas para o estabelecimento de um novo status para os cursos de formação e, como política de incentivo à profissão de magistério. Esses mesmos autores afirmam ainda, que o programa visa estimular a docência pelo fomento de ações a serem desenvolvidas dentro das escolas públicas da educação básica por licenciandos, juntamente com os professores dessas instituições e os professores das universidades.

De acordo com Braibante e Wollmann (2012) [7], o PIBID permite o contato dos professores em formação inicial com a realidade escolar desde sua graduação, de forma diferenciada, contribuindo para um amadurecimento da docência ao longo de sua formação, preparando-os para o futuro campo de trabalho.

Embora o PIBID tenha sido lançado há pouco tempo, em 2008, algumas pesquisas já se direcionam a estudar as suas contribuições para a formação inicial de seus bolsistas. Paredes e Guimarães (2012) [6], por exemplo, estudaram as compreensões e os significados sobre o PIBID para a melhoria da formação inicial de professores de Biologia, Física e Química em uma universidade do estado do Paraná. A análise foi feita a partir dos objetivos, das ações realizadas no âmbito deste programa entre 2010 e 2011 e, das entrevistas com um professor supervisor de cada um desses subprojetos. Os autores concluíram que o PIBID é entendido como um espaço que possibilita a integração entre a universidade e a escola, no escopo da melhoria da formação inicial docente. Foi concluído ainda, que o PIBID permite aos professores em formação inicial o entendimento e a reflexão sobre a profissão docente e também sobre a realidade da escola, por meio do desenvolvimento de unidades didáticas que privilegiam a inserção de diferentes materiais e abordagens didáticas inovadoras no ensino de ciências, abordagens essas que são defendidas por pesquisas sobre o ensino de ciências, como o uso da filosofia e história da ciência, abordagem ciência-tecnologia-sociedade e das novas tecnologias de informação e comunicação, tratando a escola da educação básica como um campo de investigação e de aplicação dessas estratégias. 
Braibante e Wollmann (2012) [7] estudaram as contribuições do PIBID para a formação inicial e continuada de seus bolsistas por intermédio das atividades que foram desenvolvidas durante a execução do projeto, e também através da interação com professores e alunos da educação básica e da articulação entre a universidade e as escolas. Foi analisado também o relato dos bolsistas no final das atividades do PIBID, a respeito de sua participação no programa e da consequência do PIBID em sua formação acadêmica. Conclui-se que o programa influenciou de maneira significativa no futuro profissional dos acadêmicos envolvidos no projeto. Os licenciandos despertaram um maior interesse pela docência, o que segundo as autoras, permite acreditar que esses profissionais apresentarão uma atuação diferenciada.

A partir do exposto anteriormente, nota-se que o programa tem causado impactos positivos na formação inicial docente.

\section{O PIBID na Universidade Investigada}

O projeto contava, à época, com a participação de 20 licenciandos (bolsistas) divididos em 4 subgrupos, sendo que cada subgrupo se refere a uma das escolas participantes; 4 professores supervisores das escolas participantes (bolsistas); 1 professor universitário, denominado coordenador de área (bolsista); e 2 professores universitários, denominados orientadores de subgrupos (não bolsistas).

Algumas das atividades realizadas pelo PIBID/Química da Universidade participante da presente pesquisa e que visam contribuir para a formação dos bolsistas envolvidos são as unidades didáticas (UDs), os estudos dirigidos, as oficinas didáticas e minicursos, a produção de um diário de campo e a produção de material didático (kits experimentais e unidades didáticas escritas).

As UDs são sequências de aulas sobre um determinado conteúdo. Essas unidades são planejadas e ministradas pelos licenciandos, sob orientação do orientador do PIBID, do coordenador e do professor supervisor da escola parceira.

Depois de aplicada a UD, analisa-se o que deve ser alterado na mesma. Em seguida, a UD é escrita para que outros professores possam utilizá-la e todos os materiais produzidos e empregados durante a aplicação da mesma são anexados. Os experimentos realizados durante a aplicação da UD se tornam kits experimentais, que são disponibilizados para os pibidianos, para os professores da educação básica e para os estagiários. Por meio das UDs, os licenciandos aprendem a planejar sequências de aulas, ministrar aulas e avaliar o planejamento e suas práticas didáticas. Algumas das UDs aplicadas podem ser acessadas por meio do livro organizado por Suart (2014) [8].

Os estudos dirigidos são encontros nos quais se realizam discussões sobre um texto, de relevância para a formação de professores. Cada subgrupo coordena a discussão de um texto e esses encontros ocorrem periodicamente. As oficinas didáticas e minicursos ocorrem no sentido de trazer discussões pertinentes para a formação de professores e ao Ensino de Química, tratando, às vezes, de abordagens diferenciadas para se ensinar Química. Simultaneamente a todas essas atividades, os licenciandos escrevem um diário de campo, no qual refletem criticamente sobre cada uma das atividades realizadas, seus pontos satisfatórios e os pontos que deixaram a desejar, e quais contribuições elas trouxeram para suas formações.

\section{METODOLOGIA}

A pesquisa realizada nesse trabalho é considerada uma pesquisa qualitativa. Segundo Neves (1996) [9], a pesquisa qualitativa costuma ser direcionada enquanto é desenvolvida. Além disso, de acordo com esse mesmo autor, o foco de interesse da pesquisa qualitativa é amplo e a sua perspectiva é diferente da perspectiva adotada pela pesquisa quantitativa, uma vez que, ela não procura enumerar ou medir eventos e, geralmente, não se utiliza da estatística para analisar seus dados. Os dados coletados nesse tipo de pesquisa se caracterizam por serem descritivos e obtidos por meio do contato direto e interativo do pesquisador com o objeto de estudo [9]. 
De acordo com Ludke e André (1986) [10], a entrevista é uma das principais técnicas de trabalho empregadas em pesquisas realizadas nas ciências sociais. As mesmas autoras ainda definem dois tipos de entrevistas: as entrevistas estruturadas e as não-estruturadas ou semiestruturadas, afirmando que entrevista semi-estruturada parece ser mais apropriada para o trabalho de pesquisa que se faz em educação na atualidade.

As entrevistas semi-estruturadas, ainda de acordo com Ludke e André (1986) [10], ocorrem a partir de um esquema previamente estabelecido, mas não aplicado de forma rígida, permitindo ao entrevistador fazer adaptações necessárias ao longo do desenvolvimento da entrevista. Assim, pode-se observar a relevância do uso da entrevista em pesquisas relacionadas à educação.

Os dados foram coletados por meio de uma entrevista semi-estruturada, de duração aproximada de trinta minutos, com alguns integrantes do PIBID. As questões contemplavam aspectos relacionados à razão de escolha pelo curso de licenciatura, os interesses, contribuições e expectativas pelo PIBID, interesse pela docência e contribuições do PIBID para a formação docente dos seus integrantes que responderam as entrevistas.

Participaram das entrevistas, onze bolsistas e uma licencianda voluntária, totalizando doze entrevistas. Foi considerado que o grupo de entrevistados deveria contemplar: a. a participação de ao menos um licenciando de cada subgrupo; b. integrantes que participavam do programa desde que esse iniciou na Instituição; c. integrantes que ingressaram algum tempo após o seu início; d. a participação da licencianda voluntária, uma vez que a bolsa concedida não se tratava um de seus principais interesses pelo Programa.

As entrevistas foram gravadas e transcritas e atribuídos codinomes aos entrevistados, a fim de se preservar a identidade dos mesmos. É importante salientar que os entrevistados assinaram um termo de autorização concordando com sua participação na pesquisa, bem como, consentindo a utilização dos dados para pesquisa e publicação. Ainda, a pesquisa está registrada no Comitê de Ética e Pesquisa da Universidade foco desse trabalho (CAEE 14508013.8.0000.5148/ Parecer: 257.408).

Foram analisadas as respostas dadas a cada uma das questões apresentadas acima e, pontos considerados relevantes ao desenvolvimento dessa pesquisa são discutidos e apresentados em Análise das Entrevistas, por meio de três categorias propostas: A visão dos licenciandos sobre o magistério e o curso de Licenciatura em Química da instituição participante da pesquisa; As motivações dos licenciandos ao ingressarem no PIBID/Química dessa instituição e, Contribuições do projeto para a formação docente.

$\mathrm{Na}$ categoria "A visão dos licenciandos sobre o magistério e curso de Licenciatura em Química da instituição participante da pesquisa" foram enquadradas as respostas que demonstraram opiniões dos licenciandos em relação ao curso de Licenciatura em Química da instituição, bem como os objetivos iniciais dos mesmos ao ingressarem no curso. A categoria "As motivações dos licenciandos ao ingressarem no PIBID/Química" enquadra as respostas dadas pelos licenciandos quando questionados sobre seus objetivos iniciais, e também, seus objetivos atuais em relação ao PIBID. A categoria "Contribuições do projeto para a formação docente", enquadra as respostas nas quais os estudantes relatam aspectos referentes às suas formações iniciais enquanto professores, antes e após as suas participações no PIBID, e seus interesses em lecionar ou não na educação básica desde quando ingressaram no programa, bem como os objetivos atuais dos licenciandos em relação a suas futuras atuações profissionais, a saber, a docência na educação básica ou superior, além de apresentar a opinião dos licenciandos sobre a contribuição dos professores supervisores, dos professores orientadores e da coordenação do PIBID para sua formação docente.

As citações extraídas das entrevistas e apresentadas na análise podem não apresentar parte de seus conteúdos, uma vez que se foram evidenciadas na discussão apenas as partes consideradas importantes ao desenvolvimento da mesma. Foram mantidas durante as transcrições as expressões características da linguagem falada, portanto, as entrevistas podem apresentar, em certos pontos, um distanciamento da linguagem culta escrita. 


\section{ANÁLISE DAS ENTREVISTAS}

As respostas dadas a cada questão foram analisadas e enquadradas nas três categorias já citadas na metodologia.

A visão dos licenciandos sobre o magistério e curso de Licenciatura em Química da instituição participante da pesquisa

As respostas às primeiras questões da entrevista puderam ser enquadradas nessa categoria, uma vez que se relacionavam ao motivo pelo qual os entrevistados escolheram o curso de Licenciatura em Química e se os mesmos sabiam que o curso se destinava a formar professores. Pôde-se observar que quatro dos licenciandos entrevistados (33\%) sabiam que o curso se destinava a formar professores e almejavam, inclusive, lecionar na educação básica. Essa motivação, de acordo com os entrevistados, veio de influências positivas de seus professores de ensino médio.

Um exemplo pode ser observado na fala da bolsista Clara:

"A:: porque eu me inspirava nos meus professores de ensino médio. Eu queria ser COMO eles. Ai para eu escolher Química, foi porque eu queria ser professora mesmo".

O bolsista Ricardo também relata uma experiência semelhante:

"Eu sai do ensino médio com uma experiência muito boa de Química, com os meus professores de Química, e acabei me interessando pela área de Ensino de Química assim. Ser professor de Química mesmo".

No entanto, nem todos os entrevistados manifestaram esse conhecimento em relação ao objetivo de um curso de licenciatura e não tinham interesse de lecionar na educação básica quando ingressaram no curso. Quatro licenciandos entrevistados (33\%) argumentaram que queriam fazer um Curso de Química. A fala da bolsista Stella pode exemplificar esse fato:

"Na verdade $(++)$ eu não sabia exatamente $(+)$ o que significava (+) ser um curso de licenciatura. Na verdade eu escolhi Química, mas eu não sabia ao certo o que isso implicava".

Uma situação interessante foi encontrada na fala da bolsista Juliana. Essa licencianda afirma que sabia que o curso formava professores, mas que só se interessou pela docência ao longo do curso:

"Na verdade, EU ESCOLHI por gostar de QUÍMICA (++) e a licenciatura eu fui tomando gosto depois que eu entrei no curso".

Outro caso que se destacou foi o do licenciando Jhonatan. Esse bolsista afirmou ter entrado no curso se Licenciatura em Química sabendo que era licenciatura, porque queria fazer qualquer curso na área de Química.

"Eu entrei pelo fato de ser Química. É::: no ensino médio era uma matéria que eu tinha afinidade. (...) eu sabia que ia fazer Química. Eu passei aqui mas inicialmente eu queria Química, não importando o curso que era".

Três licenciandos (25\%) manifestaram conhecimento em relação ao objetivo do curso em formar professores. Entretanto, eles também sabiam que teriam outras oportunidades além da docência por meio do curso. Esse fato pode ser observado na fala da bolsista Luciana:

"Mas eu sabia que era um curso de licenciatura, que era para dar aula, mas que eu teria outras opções".

Pode-se notar a partir das afirmações desses três últimos licenciandos que, embora os mesmos tenham ingressado conscientemente na licenciatura, não há interesse inicial na docência. Esse fato pode se originar na desvalorização do magistério pela sociedade. A fala do bolsista Miguel pode exemplificar essa questão:

"Eu fui um pouco induzido também pela minha família porque dentro da minha família existe uma grande carga de pessoas voltadas para a educação, desde pedagogos até professores e:: todos eles achavam que eu estava fazendo besteira indo para a licenciatura."

Assim, observa-se a falta de informação dos alunos quanto ao curso que frequentariam. Esse fato pode trazer consequências para o aluno e também para a universidade, já que o licenciando pode perceber, em um curto prazo, que está no curso indesejado e desistir deste, ocasionando o 
elevado número de evasão de alunos ingressantes, observado nos últimos anos, principalmente quando relacionado aos cursos de licenciatura. Por esse motivo, as Universidades têm de se esforçar para manter os alunos no curso, criando programas e medidas de incentivo, até porque uma vaga não preenchida gera uma grande despesa para o ensino público (Machado, Filho e Pinto (2005) [11]).

\section{As motivações dos licenciandos ao ingressarem no PIBID/Química}

Considerando os objetivos iniciais em relação ao PIBID, oito dos licenciandos entrevistados (67\%) afirmam buscar no projeto, melhorias para sua formação inicial como docente, como pode ser notado na fala da bolsista Clara:

"Eu procurava uma formação (+) melhor para ser professora. Tipo, ir para a escola, dar aula, (+) eu me interessava por aplicar projetos e ver o resultado daquilo".

A bolsista Helena afirmou que procurava um contato maior com a escola:

"Ter o contato né? Antes do estágio, poder trabalhar nas escolas com os professores, vendo a realidade como é".

Os objetivos apresentados pelas bolsistas Clara e Helena se enquadram muito bem no objetivo do PIBID apresentado pelo MEC, ou seja, o de antecipar o vínculo entre salas de aula da rede pública e futuros docentes, presumindo que licenciandos participem das atividades realizadas pelas escolas participantes do programa.

Outros dois licenciandos afirmam que procuraram ingressar no projeto por causa da bolsa que é oferecida. A bolsista Adrielle afirma, no entanto, que procurou o projeto inicialmente pela bolsa, mas que também esperava contribuições do projeto para a sua formação:

"Ter o contato com a escola, porque é diferente o estágio do PIBID. Você teria ((no PIBID)) um melhor contato com o ambiente escolar".

A mesma bolsista afirma ainda que foi o PIBID que a impediu de desistir do curso de Licenciatura em Química, uma vez que o programa surgiu como uma oportunidade para que ela tivesse certeza sobre qual área ela queria seguir. Esse fato pode ser notado na fala da bolsista sobre seus objetivos além da bolsa e da melhoria na formação inicial:

"Também para ver se era isso que eu queria. A bolsa veio e eu falei: Vou ficar para saber se é isso ou se eu vou sair mesmo. O PIBID acabou servindo para eu ficar. Depois que eu entrei eu não quis mais sair do curso"

Duas outras entrevistadas afirmaram que procuraram o PIBID para ter contato com a área de Ensino de Química, e consequentemente, descobrir se gostariam ou não daquela área. Esse fato pode ser notado na fala da bolsista Michelle:

"Resolvi tentar entrar para ver se era isso mesmo, se eu ia gostar mesmo dessa área de ensino."

Embora todos os entrevistados tenham afirmado que o valor da bolsa é bem significativo, alguns declaram que a existência da bolsa não foi um fator determinante, havendo bolsistas que alegam que participariam do projeto mesmo que ele fosse voluntário ou se a bolsa tivesse um valor menor. Cabe ainda ressaltar que uma das licenciandas participantes do projeto abandonou uma bolsa de iniciação científica para se dedicar voluntariamente ao PIBID.

Procurando investigar se a participação no programa gerou mudanças nos objetivos dos bolsistas em relação ao mesmo, os entrevistados foram questionados sobre isso. Quatro licenciandos (aproximadamente 33\%) afirmam que seus objetivos iniciais mudaram pouco, foram apenas aprimorados, como pode ser visto na fala da bolsista Stella:

"Ainda espero as mesmas coisas e vejo que tem funcionado. Está me auxiliando nessa questão de planejar, de executar o planejamento, de repensar o planejamento... Nessa forma de atuar...".

Assim como a bolsista Stella, os outros entrevistados focalizam bastante na questão do planejamento das atividades e execução do que foi planejado como uma grande contribuição do PIBID para as suas formações.

A bolsista Helena afirma que seus objetivos mudaram no sentido de que, atualmente, ela tem mais certeza do que quer para sua vida profissional: 
"Mudou um pouquinho porque quando eu comecei eu ficava meio assim, será que eu quero esse futuro para mim? Agora estou vendo que posso fazer diferente".

Apenas quatro bolsistas (aproximadamente 33\%) afirmaram que seus objetivos mudaram totalmente depois que eles ingressaram no PIBID. Um exemplo é a fala pertencente à bolsista Adrielle:

"Mudou sim porque foi graças a ele que eu continuo em Química e::: hoje eu gosto das atividades, eu gosto do programa"

Nota-se por essa citação que a participação no projeto trouxe mudanças positivas nos objetivos dos licenciandos envolvidos no mesmo, o que pode significar um amadurecimento dos professores em formação inicial em relação à docência, seja na educação básica, superior ou técnica.

\section{Contribuições do projeto para a formação docente}

Considerando o PIBID como um programa que procura valorizar a formação inicial de professores para a educação básica, julgou-se importante questionar os entrevistados para saber se eles tinham interesse em lecionar ou não na educação básica quando ingressaram no programa. Dois afirmam que já tinham esse interesse e que foi justamente por isso que procuraram participar do PIBID, como é o caso da licencianda Luíza:

"Por isso mesmo que eu entrei. Para aprender como lidar com os alunos, para aprender a dar aula mesmo né?"

A fim de se conhecer os impactos do PIBID na formação dos pibidianos, os licenciandos foram questionados sobre como veem sua formação inicial atualmente. Todos os entrevistados afirmam que se sentem mais preparados para a docência. $\mathrm{O}$ licenciando Jhonatan relata que:

"Tudo o que foi feito desde que eu entrei no projeto até agora acrescentou de maneira considerável. Sobretudo a postura que a gente deve ter, não ter a visão do professor como aquele que vai passar o conhecimento"

O mesmo licenciando diz que o PIBID ajuda a entender a necessidade de que o professor assuma uma postura construtivista:

"A gente vê a importância de o professor construir com os alunos o conhecimento, aprender com o aluno e também compartilhar o conhecimento que a gente tem com eles".

O licenciando ressalta ainda que:

"É importante conhecer um pouco sobre a cultura daquela escola, daquela sala de aula, $e$ procurar em cada um os potenciais que eles têm a oferecer"

Essa visão do que é ser professor é congruente ao que é definido por Castro e Carvalho (2001) [12], uma vez que a autora afirma que o professor atua como um agente de valores, ou seja, ele influencia as atitudes e os comportamentos dos alunos.

A licencianda Luciana afirma que se encontra muito mais preparada para a docência, mas que ainda tem algumas coisas para aprender. O relato dessa licencianda, apresentado a seguir, exemplifica essa questão:

"A gente sempre tem muito que aprender, mas minha formação hoje está bem melhor, está muito boa. Aprendi muita coisa. Não só como dar aula. Acho que é isso, mas eu posso falar que hoje a minha formação é muito boa".

Nota-se também que a bolsista Adrielle ainda tem receio de não conseguir enfrentar as dificuldades relacionadas à docência, embora atualmente se sinta mais preparada:

"Eu me vejo mais preparada, mas com aquele mesmo medo de não dar conta por causa das dificuldades. Mas muito mais preparada, com muito mais/ muito mais vontade de (incompreensivel) de poder lidar com os alunos".

É consenso entre os entrevistados que o PIBID contribui mais para a formação inicial do que os estágios supervisionados. Segundo os licenciandos, isso se deve ao fato de que o PIBID proporciona maior contato com o ambiente escolar, e concede aos mesmos uma liberdade maior dentro da sala de aula, permitindo, por exemplo, que os mesmos ministrem várias aulas. É destacado também que dentro do PIBID aprende-se a planejar desde uma aula até sequências de 
aulas e, que por meio dos estudos dirigidos, é possível uma apropriação teórica extremamente relevante para a docência.

O licenciando Ricardo, por exemplo, se focaliza no planejamento:

"A forma como a gente planeja, de estudar, e que eu tenho que planejar a aula, a tentativa de sempre chamar o aluno para prestar atenção na aula, sempre faz a gente reformular e a gente vai conseguindo fazer uma aula melhor, um planejamento melhor".

O mesmo bolsista em outro momento relata sobre a importância dos estudos dirigidos para a apropriação de teorias:

"Os estudos dirigidos foram muito importantes. Faltava muito dessa apropriação teórica mesmo para a gente."

A licencianda Luciana chama atenção também para a questão das pesquisas realizadas dentro do projeto:

"No PIBID a gente produz, a gente escreve, e no estágio não teria isso, mas eu acho que o estágio também tem sua contribuição. A do PIBID é maior, mas o do estágio também é bem grande na formação inicial"

Quando questionados sobre como o PIBID contribui para a formação inicial de seus bolsistas, todos afirmam que o PIBID contribui muito, permitindo um contato maior com a realidade escolar e complementando aprendizagens durante a graduação. O bolsista Ricardo afirma que o PIBID o auxiliou com:

"Uma visão geral de tudo. Posso usar todos os livros didáticos ou posso não usar nenhum, eu posso pegar um de ensino superior e usar para preparar minhas aulas".

Nota-se então que o PIBID/Química traz impactos positivos na formação dos licenciandos que participam do mesmo. Esses resultados condizem com os resultados encontrados por outros autores, como por exemplo, Braibante e Wollmann (2012) [7], Paredes e Guimarães (2012) [6]

Questionando ainda os licenciandos sobre o interesse em lecionar na educação básica, notouse pelas respostas que existe uma divisão entre os licenciandos que querem lecionar na educação básica e os que almejam cursar a pós-graduação. Seis licenciandos entrevistados (50\%) manifestaram interesse por lecionar na educação básica, no entanto, só o bolsista Jhonatan, explica o porquê:

"tudo o que o PIBID oferece para a formação do professor eu acho que é um incentivo para que nós bolsistas cheguemos na sala de aula e não desenvolvamos somente os conteúdos específicos que se pede, mas também desenvolver o lado social do aluno".

Observa-se que dois bolsistas (aproximadamente 16\%) deixam a docência em segundo plano frente à pós-graduação. A bolsista Clara afirma:

"eu daria aula sim, mas eu quero fazer um mestrado na área de ensino, um doutorado. Mas se eu tiver oportunidade. Se eu não tiver e tiver que dar aula na escola pública eu dou, com a perspectiva que o PIBID me ensinou".

O licenciando Ricardo afirma ainda não saber se pretende lecionar ou fazer uma pósgraduação:

"Se vou fazer pós-graduação ou trabalhar eu ainda não sei. Isso vai depender de como eu vá. Porque às vezes eu fique cansado de estudar e decido que quero trabalhar mesmo. Aí eu vou trabalhar na escola."

A bolsista Ana Flávia afirma que lecionaria sim na educação básica, mas que prioriza lecionar em uma escola técnica em sua cidade, na qual a própria bolsista já estudou.

Um caso interessante é o da bolsista Stella, que quando entrou no PIBID tinha interesse em lecionar na educação básica, e atualmente não tem mais. Questionada sobre o porquê dessa mudança, ela afirma:

"Eu não sei se é pelos alunos, ou se é pelo sistema que cobra muito/ a gente vê os professores falando que tem que escrever no diáriol tem muitas atribuições (...). Até mesmo pelo salário".

A fala da bolsista Stella mostra que a remuneração é um fator que desmotiva a docência na educação básica. Além disso, o fato de a bolsista ter desistido de lecionar na educação básica ao se deparar com tantas dificuldades não é algo inédito. Gaspari (2008) [13] já havia percebido 
que o contato com a realidade escolar durante um estágio supervisionado pode fazer com que os licenciandos se desmotivem pela docência.

Outros dois licenciandos (16\%) não querem lecionar na educação básica. É válido ressaltar que esses bolsistas já não apresentavam interesse pela docência desde quando ingressaram no curso de licenciatura. Merece atenção o fato de que um desses dois bolsistas disse que considera um erro lecionar na educação básica ao sair da graduação:

"Eu acho que a gente, simplesmente não pode parar por aqui, eu acho que simplesmente sair daqui e ir para a escola é um erro. (++) É um erro grave. A palavra diz, é uma formação inicial".

O bolsista explica sua posição argumentando que:

"essa formação inicial tem carência de coisas importantes, e é necessário um amadurecimento maior em outras coisas que foram aprendidas".

Considerando a explicação dada pelo bolsista, é necessário que todos os profissionais universitários que se relacionam com as licenciaturas, se envolvam mais para que sejam sanadas essas lacunas sentidas por esse bolsista e, provavelmente, por outros licenciandos não entrevistados.

Considerando que $75 \%$ dos entrevistados responderam que tinham interesse em lecionar na educação básica quando ingressaram no PIBID, e que atualmente essa porcentagem tenha reduzido para $50 \%$, percebe-se que houve uma desmotivação dos licenciandos ao longo de suas participações no projeto. Esse fato era inesperado, já que o PIBID é um programa que visa incentivar a docência na educação básica. No entanto, o PIBID não parece ser a razão pela desmotivação, e sim a desvalorização dos professores da educação básica, como foi dito pela bolsista Stella, ao falar sobre o motivo e de não querer mais lecionar na educação básica:

"O professor ((da educação básica)) não é muito valorizado".

Parece necessário, portanto, que medidas sejam tomadas a fim de que a docência na educação básica seja valorizada. Caso contrário, apesar da existência do PIBID, que incentiva a docência na educação básica, os licenciandos possivelmente continuarão priorizando a pós-graduação e a docência no ensino superior.

Ao serem questionados sobre as contribuições que os professores supervisores trazem para suas formações como professores, todos os licenciandos afirmam que a presença dos supervisores é muito importante, pois traz as experiências de quem já está no ambiente escolar. Esse fato pode ser notado na fala da bolsista Helena:

"É muito bom. Eu aprendo muito com a supervisora do nosso subgrupo, eu fico vendo a maneira como ela trabalha dentro da sala de aula. Sabel a postura dela. Ela é uma influência para a gente".

Quanto às contribuições vindas do orientador do subgrupo, os entrevistados afirmam que as contribuições positivas são muito significativas. As palavras do licenciando Miguel podem exemplificar esse fato:

"Ele traz uma coisa interessante para o grupo, às vezes nós estamos com certo olhar sobre determinada coisa. Ele vem com outro olhar e expande nosso campo de visão".

Em relação às contribuições trazidas pela coordenação de área, a resposta dos entrevistados foi unânime no sentido que só existem contribuições positivas, e destacam o fato de a coordenadora ser da área de Ensino de Química. As palavras do bolsista Ricardo retratam bem isso:

"Essa visão mais focada, no grupo todo faz muita diferença. O pessoal fazia muitas coisas desencontradas. Quando a atual coordenadora começou a orientar, a gente passou a ter uma visão mais prática do que fazer, porque fazer".

O bolsista fala ainda sobre as contribuições que as atividades propostas pela coordenação trazem para a formação docente:

"Os estudos dirigidos foram muito importantes. Faltava muito dessa apropriação teórica, a importância de ter um cronograma, de se orientar (++) planejar, e que planejamento não sai à risca também né?". 


\section{CONSIDERAÇÕES FINAIS}

Por meio desse trabalho observou-se que o projeto PIBID traz impactos positivos na formação inicial dos licenciandos envolvidos, uma vez que os mesmos afirmam que se sentem mais preparados para a docência.

Durante as entrevistas, os estudantes fazem constantes comparações entre os estágios supervisionados e o PIBID. Isso direciona a um questionamento sobre a diferença entre as atividades do PIBID e as atividades do estágio. Os licenciandos afirmam, unanimemente, que nos estágios tem-se um contato menor com a realidade escolar, e que muitas das vezes, os mesmos são apenas de observação.

Um fato a questionar é que os licenciandos afirmam que os estágios são insuficientes para direcionar os futuros professores para a sala de aula. É necessário que pesquisas futuras sejam feitas para entender os motivos dessa e de outras afirmações que surgiram durante as entrevistas, mas que não englobavam o objetivo desse trabalho.

Considerando os objetivos do MEC de antecipar o vínculo entre os futuros professores com escolas da rede pública envolvendo-os nas atividades realizadas pelas escolas participantes do programa, conclui-se que existe uma concordância, ainda que não unânime, entre os objetivos do MEC e do projeto aqui avaliado.

No entanto, foi possível notar que a desvalorização da docência na educação básica vem desmotivando os licenciandos. Por esse motivo, faz-se necessário que medidas sejam tomadas a fim de se valorizar os profissionais que atuam, e que atuarão, como docentes no ensino básico.

\section{REFERÊNCIAS BIBLIOGRÁFICAS}

1. Maldaner OA. A Formação Inicial e Continuada de Professores de Química: Professores/Pesquisadores. Ijuí: Ed. Unijuí; 2006. 419 p.

2. Pereira JED. As licenciaturas e as novas políticas educacionais para a formação docente. Educação \& Sociedade, 1999; 20(68): 109-125.

3. Schnetzler RP, Aragão RM. Importância, sentido e contribuições de pesquisas para o ensino de química. Química Nova na Escola. 1995 maio;1: 27-31.

4. Benite CRM, Benite AMC, Echeverria AR. A Pesquisa na Formação de Formadores de Professores: Em Foco, a Educação Química. Química Nova na Escola, 2010 nov; 32(4): 257-266.

5. Ministério de Educação e Cultura [homepage na internet]. Programa Institucional de Bolsas de Iniciação à Docência (Pibid) [acesso em 18 de dez 2014]. Disponível em: http://portal.mec.gov.br/index.php?option=com_content\&view=article\&id=233:pibidapresentacao\&catid $=155$ :pibid\&Itemid $=467$

6. Paredes GGO, Guimarães OM. Compreensões e Significados sobre o PIBID para a Melhoria da Formação de Professores de Biologia, Física e Química. Química Nova na Escola, 2012 nov; 34(4): 266277.

7. Braibante MEF, Wollmanm EM. A Influência do PIBID na Formação dos Acadêmicos de Química Licenciatura da UFSM.Química Nova na Escola, 2012 nov; 34(4): 167-172.

8. Suart RC. organizadora. Unidades Didáticas para o Ensino Médio de Química: Propostas para a Prática Docente Inicial e Continuada. São Carlos: Pedro \& João Editores; 2014. 122 p.

9. Neves JL, Pesquisa Qualitativa- Características, Usos e Possibilidades. Caderno de Pesquisa em Administração, 1996; 1(3): 1-5.

10. Ludke M, André MED. A. Pesquisa em educação: abordagens qualitativas. São Paulo: EPU, 1986.99 p.

11. Machado SP, Filho JMP. Pinto AC. A evasão nos cursos de graduação de Química. Uma experiência de sucesso feita no Instituto de Química da Universidade Federal do Rio de Janeiro para diminuir a evasão. Química Nova, 2005 nov. dez.; 28.

12. Castro. AD.: Carvalho. AMP. Ensinar a Ensinar: Didática para a Escola Fundamental e Média. São Paulo: Cengage Learning, 2001.Capítulo 5. o papel do professor na sociedade digital; p. 95-106.

13.Gaspari AR. A formação de professores de Química em curso de Licenciatura [dissertação]. São Paulo: - Universidade de São Paulo; 2008.86 p. 